\title{
Optimization Design of Groundwater Level Monitoring Network Based on the Geo-Statistics
}

\author{
Chen Jing \\ School of Earth Science \& Engineering , Hohai University, Nanjing , Jiangsu , 210098, China \\ juzi17@163.com
}

Keywords: groundwater monitoring network; geo-statistics theory; optimization design; precision requirement.

\begin{abstract}
The current groundwater monitoring network has many problems caused by the history and poor techniques, which has provided incomplete groundwater information and it is adverse to the management of groundwater resources. So it is necessary to optimize it. The writer takes the deep pore confined water monitoring network in Ningbo Plain as an example ,using the main two parts of geo-statistics - variogram and Kriging interpolation to adjust the number and position of the current 29 wells on it, finally getting a new more reasonable monitoring network consists of 19 wells after removing 17 redundant wells and adding 7 new wells.
\end{abstract}

\section{Foreword}

The data of groundwater regime can reveal its flow law ${ }^{[1]}$, help the decision makers manage groundwater resources effectively and guarantee the sustainable utilization of groundwater resources, so it's very important to make a economical and high efficient monitoring network for acquiring data of groundwater regime. With the urbanization process keep going, the current monitoring networks expose some problems ${ }^{[2]}$ which can not help to get complete and accurate data and this will impede the development of economic social, needing to be optimized right now.

All of the problems of the current well network, the main is that the layout of wells is not very reasonable. Fortunately, the geo-statistics set up by the French statisticians G.Matheron can well resolve such problem, and which has been used in many successful cases ${ }^{[3]}$. The paper just use this theory to optimize the spatial layout of wells on Ningbo Plain' deep pore confined aquifer, and the optimal solution.

\section{Principle of Geo-Statistics}

Geo-statistics is science which is based on the theory of regionalized variable, taking variogram as the basic tool and using Kriging method to research natural phenomenon which both have randomness and constitutive property in spatial distribution. It consists of Kriging interpolation and variogram.

Kriging Interpolation. Kriging interpolation is mainly used to make optimum linear unbiased estimation of regionalized variable in limited area ${ }^{[4]}$. Assuming that there have gotten $\mathrm{N}$ observed values $\mathrm{Z}\left(\mathrm{x}_{\mathrm{i}}\right)(\mathrm{i}=1 \sim \mathrm{N})$ of regionalized variable $\mathrm{Z}(\mathrm{x})$ in a region, then, the value of any unknown point $\mathrm{x}_{0}$ in this region can be estimated by the following equation,

$$
Z *\left(x_{0}\right)=\sum_{i=1}^{N} \lambda_{i} Z\left(x_{i}\right)
$$

Where, $Z *\left(x_{0}\right)$ is estimated value of point $x_{0}$ calculated by $Z\left(x_{i}\right), \lambda_{i}$ is the Kriging weight coefficient.

Combining with the definition of covariance, under the unbiased and best conditions, through bringing in Lagrange algorithm ,using eq.1 to estimate, which can deduce Kriging equation set as following, 


$$
\left\{\begin{array}{l}
\sum_{i=1}^{N} \lambda_{j} \gamma\left(x_{i}, x_{j}\right)+\mu=\gamma\left(x_{i}, x_{0}\right) \\
\sum_{i=1}^{N} \lambda_{i}=1 \quad(i=1 \sim N)
\end{array}\right.
$$

Where, $\gamma\left(x_{i}, x_{j}\right)$ is the variogram, $\mu$ is the lagrangian function.

Eq. 2 is used to calculate $\lambda_{i}$ and under the condition of variogram is known, it is a positive definite equations which has a unique solution.

Combing with the conversion relationship of variance function, covariance function and variogram under the condition of intrinsic condition, eq.2 can calculate theoretical variance of calculation error $\sigma^{2}$ as the following,

$$
\sigma^{2}=\sum_{i=1}^{N} \lambda_{i} \gamma\left(x_{i}, x_{0}\right)+\mu
$$

$\sigma^{2}$ just is the quantitative tool of optimizing the density of groundwater level monitoring network. First setting a critical value of variance according to the actual needs. Then calculating each point's theoretical variance by using the present observation points. The last is to compare each point's theoretical variance with the critical value of variance, the region where its theoretical variance is greater than the critical value of variance need to be added monitoring points, but to the contrary, less monitoring points are needed. Thus realizing the optimization of monitoring network.

Variogram. When $\mathrm{Z}(\mathrm{x})$ meets the intrinsic conditions, variogram in theory is calculated by type $\gamma(h)=1 / 2 \mathrm{E}[\mathrm{Z}(\mathrm{x})-\mathrm{Z}(\mathrm{x}+\mathrm{h})]^{2}$, then when there are $\mathrm{N}(\mathrm{h})$ sets of measured values whose relative distance are $h$, the experimental variogram can be calculated by using the measured values at point $\mathrm{x}_{\mathrm{i}}$ and $\mathrm{x}_{\mathrm{i}}+\mathrm{h}$ as the following,

$$
\gamma^{*}(h)=\frac{1}{2 N(h)} \sum_{i=1}^{N(h)}\left[Z\left(x_{i}\right)-Z\left(x_{i}+h\right)\right]^{2}
$$

Using eq.4 to calculate experimental variogram $\gamma^{*}(h)$ corresponding to different interval $\mathrm{h}$, and then making a curve fitting about h and $\gamma^{*}(h)$, thus $\gamma(h)$ is calculated. The $\gamma(h)$ curve always obeys distribution like Gaussian function, Exponential function, Spherical function and so on .

\section{Groundwater Monitoring Network Optimization Design of Deep Pore Confined Aquifer in Ningbo Plains}

General Situation of Optimization Area. Ningbo plain, which is a sea-proluvial plain with area of $850 \mathrm{~km}^{2}$, is located in the northeast of Zhejiang province. It is ringed on three sides by mountains and bounded in the north by the sea. The second pore confined aquifer distributed in the deep of Ningbo plain mainly consists of fluvial sandy gravel of the Middle Pleistocene Series' up formation, it has thickness of 2 to 24 meters but lost in local area. There are 29 groundwater level monitoring wells distributed within its scope of $365.74 \mathrm{~km}^{2}$.

The second pore confined aquifer is the main exploitation layer of Ningbo city's groundwater. With a long time and concentrated exploitation, there has formed a large area of landing funnel, which has changed the original groundwater flow field. To prevent the area of landing funnel further expanding, the government of Ningbo city implements the exploitation ban which has well worked. At present groundwater in the second pore confined aquifer basically flows by instinct. The paper uses the observation data of groundwater level in October 2008 which just flows by instinct.

The Map of Optimization Process. The optimization of monitoring nerwork mainly contains t- 
wo modules finished by the software Surfer and Mapgis. That is using Surfer to analyze the variance and using Mapgis to adjust the variance. The specific optimization process is shown in fig.1.

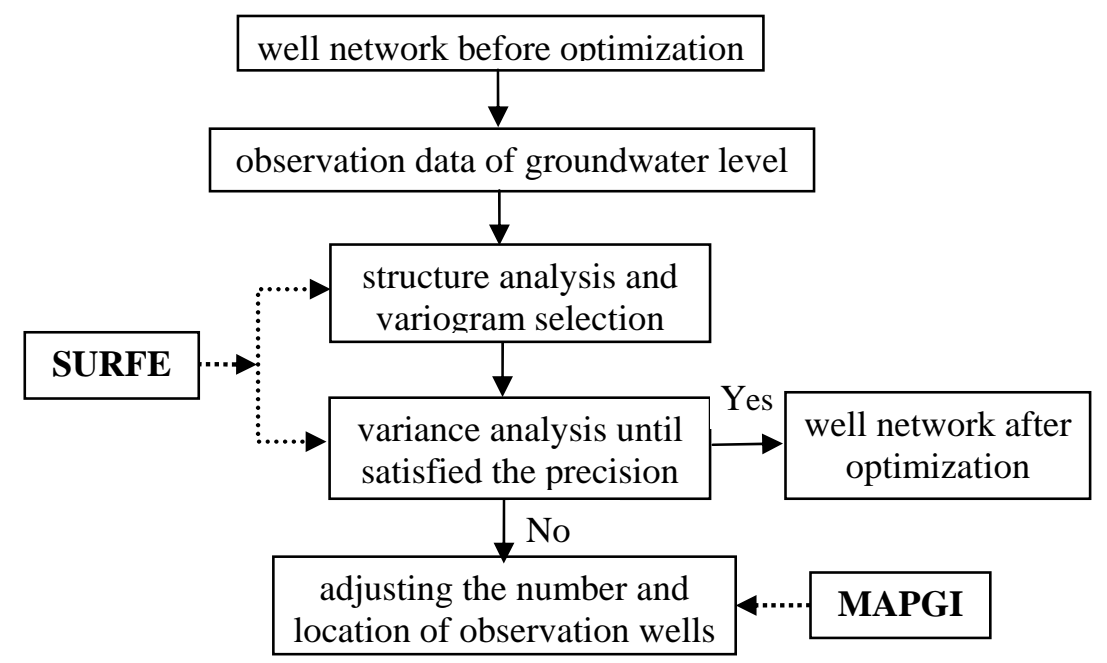

Fig. 1 The optimization process map of water level monitoring network

The Monitoring Network Optimization of Deep Pore Confined Water. The distribution sketch map of the current monitoring wells in optimization area is in shown in fig.2, the map shows that the distribution of present wells concentrate in the north of optimization area, which can not get the whole groundwater information of this area. In theory, the distribution density

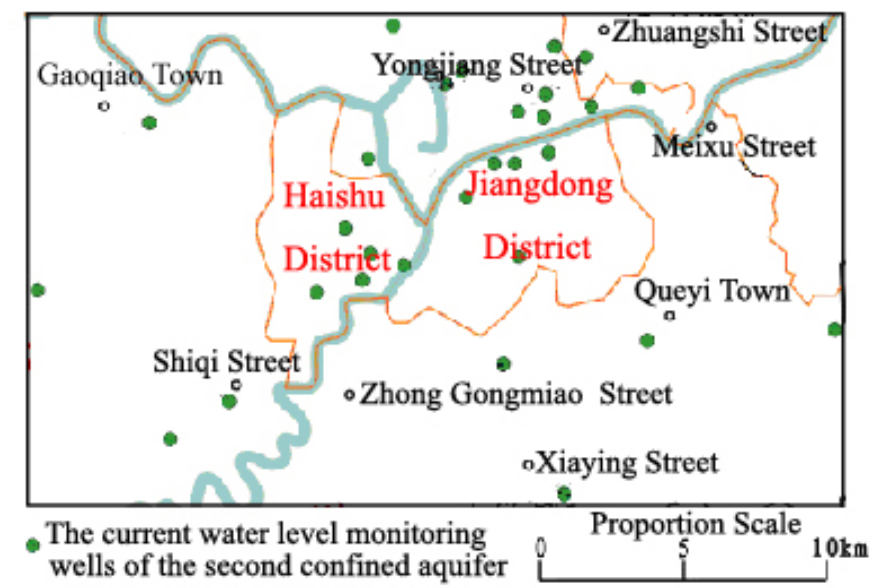

Fig. 2 Sketch map of the present monitoring wells’ distribution in optimization area

of monitoring network is larger, the groundwater information get from the monitoring network is more accurate, but this always leads to an unnecessary waste of the labour, money and material resources. There is literature ${ }^{[1]}$ pointing out that when the theoretical variance is within 0.5 to 0.6 , the accuracy of monitoring network can meet the actual needs. It also has a scope of 0.7 to 0.77 when measured by the standard deviation, the paper just optimizes the monitoring network according to this standard.

The variogram module of software Surfer fits out the variogram model of this optimization area is Gaussian model with parameters of nugget 0.1767 , sill 1.825 and range 10200 meter, which can be seen from fig.3. This which is about the selection of optimum variogram model has haven literatures ${ }^{[4,6]}$ making explanation, it's needless to explain again in the paper.

Using eq.2 to do Kriging interpolation with the variogram model getting from the above, after calculated the Kriging weight coefficient, putting it into eq.3 to calculate the theoretical variance of each observation point and then drawing its contour map. Thus the contour map of the theoretical 
variance can be used to quantitatively determine whether the density of monitoring network is reasonable or not. The paper also use the software Surfer to finish this process which is easily oper-

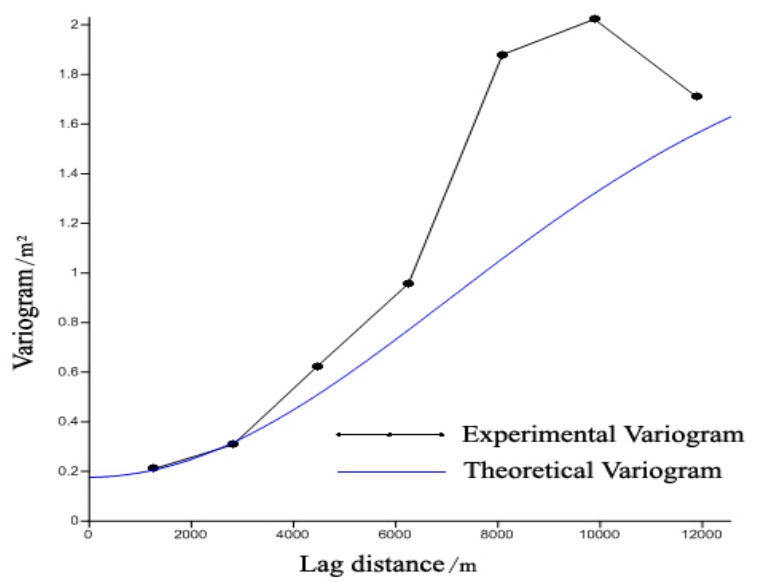

Fig. 3 Map of variogram

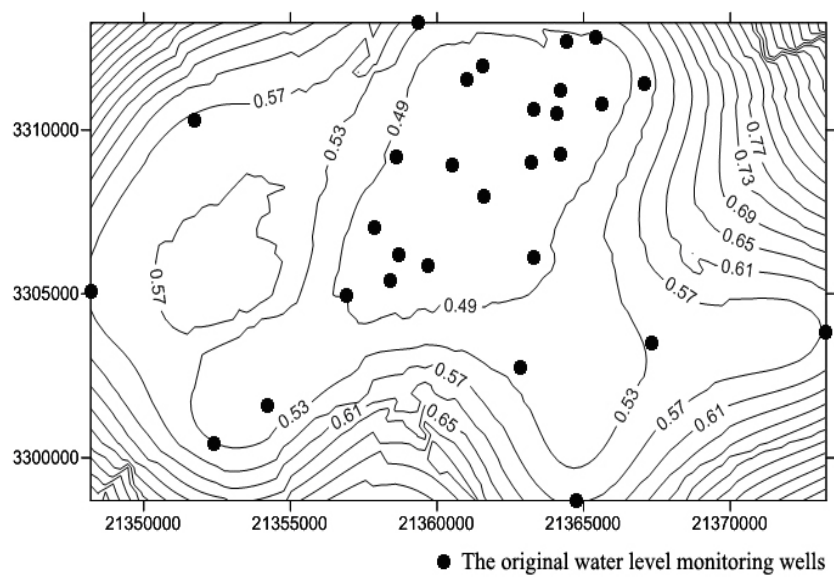

Fig. 4 The Monitoring Networ Contour map of Kriging standard deviation before optimization

ated. The kriging standard deviation map of the optimization area is shown in fig. 4. It tells us that in the north of the optimization area where monitoring wells distribute densely, the Ksd (Kriging standard deviation) are all less than 0.5, indicating the density of this area is too large, which needs to be removed some; In the four corners of the whole optimization area, the Ksd are all larger than 0.77 , indicating these areas are short of wells and need to be added wells properly.

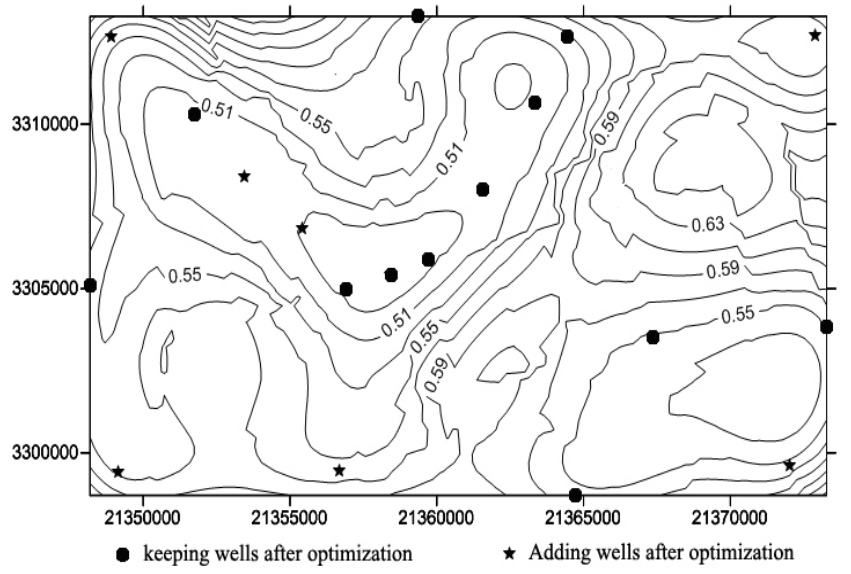

Fig. 5 Contour map of Kriging standard deviation after optimization

Aiming at the problem of the current monitoring network, the writer uses trial-and-error adjustment method ${ }^{[5]}$ to adjust it by the Mapgis software's graphic processing function. The result is deleting 17 wells and adding 7 wells after adjusting over and over again. The new monitoring network consists 
of 19 wells and its KSD contour map is shown in fig.5. From the map we can find that in the northwest of the optimization area, the KSD is quite small, even less than 0.5. This is because that there is landing funnel distributed in this area(see fig.6); In order to monitor the dynamic distribution situation of it, more wells are added at there. Except for this area, the KSD of the rest optimization area is between 0.5 to 0.77 , which meets the optimization requirement.

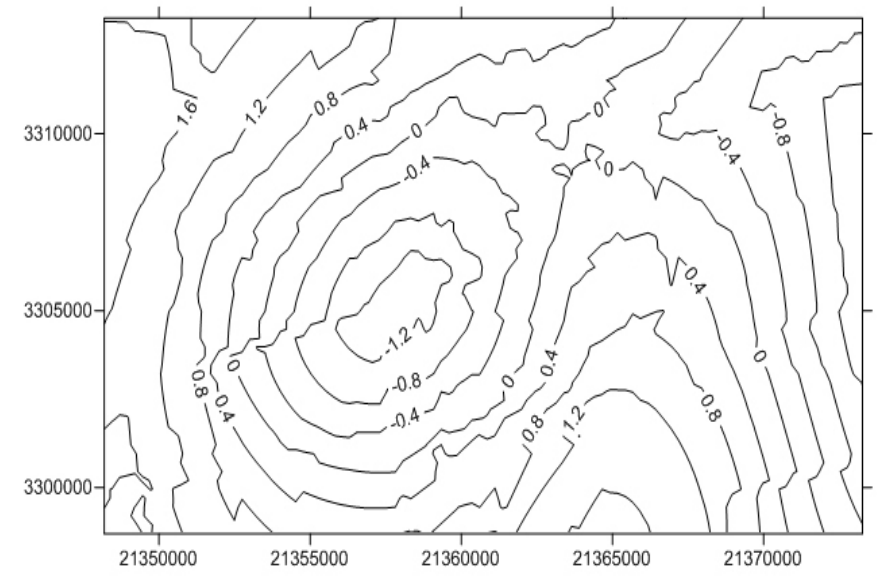

Fig. 6 Contour map of water level of the second confined aquifer

\section{Conclusion}

The method of Kriging based on the geo-statistics can quantitatively evaluate the rationality of groundwater monitoring network effectively. The paper optimizes the monitoring network of the deep pore confined water in Ningbo plain by the software Surfer' Kriging module, which is easily operated and avoids the cumbersome to write programs. To be sure, the method used in this paper is only suitable for these stable regions where they are almost not be disturbed, that is in these regions ,the groundwater flows by instinct. For those complicated regions where are hardly affected by the human beings and environment, in order to improve the calculation accuracy, the optimization of their monitoring network should build a new Kriging model which is restrained by a variety of constraints in future research.

\section{References}

[1] Tao Yue-zan, Zhen Heng-qiang, Wang Xue-fu. Assessment of groundwater monitoring network density by the Kriging method. Journal of hydrological, 2003, 23(2): 46-48. (in Chinese)

[2] Wang Ai-ping, Yang Jian-qing. The groundwater monitoring present situation analysis and prospect in our country. Journal of hydrological, 2010, 30(6): 53-56. (in Chinese)

[3] Dai Chang-lei, Chi Bao-ming. Research progress of groundwater monitoring. Journal of research of soil and water conservation, 2005, 12(2): 86-88.(in Chinese)

[4] Hou Jing-ru. Practical geological statistics. Beijing, Geology Publishing House, 1998-07.

[5] Zhou Yang-xiao, Li Wen-peng. Design of regional groundwater level monitoring networks. Journal of hydrogeology and engineering geology, 2007(1): 1-9. (in Chinese)

[6] Wu Xue-wen, Yan Lu-ming. Setting Parameters and Choosing Optimum Semivariogram Models of Ordinary Kriging Interpolation - A case study of spatial interpolation to January average temperature of Fujian province. Journal of geo-information science, 2007, 9(3): 104-108. (in Chinese) 